\title{
A RECEPÇÃO DO DIREITO ROMANO NAS UNIVERSIDADES: GLOSADORES E COMENTADORES*
}

\author{
THE RECEPTION OF ROMAN LAW IN UNIVERSITIES: GLOSSATORS AND COMMENTATORS
}

\section{Estevan Lo Ré Pousada**}

\begin{abstract}
Resumo:
O presente estudo aborda o renascimento do Direito Romano na universidade medieval, bem como a sua trajetória posterior, com a sua admissão como elemento conformador do "ius commune"; após uma breve análise sobre a evolução histórica deste direito renascido, o trabalho é encerrado com uma reflexão sobre o papel do Direito Romano na atualidade.
\end{abstract}

Palavras-chave: Direito Romano. Universidade medieval. Mos italicus. Mos gallicus. Codificação.

\begin{abstract}
:
This paper is about the rediscovery of Roman Law in medieval universities, as well as its posterior trajectory, as a conformating element of the "ius commune"; a shortanalysis about the historical development of this law was made, concluded with a reflection on the contemporary role of Roman Law.
\end{abstract}

* O presente texto corresponde à versão fidedigna da prova escrita realizada pelo autor (então candidato), durante o período de cinco horas contínuas, em concurso público voltado ao ingresso no quadro docente do Departamento de Direito Civil da Faculdade de Direito da Universidade de São Paulo (Área de História do Direito). Conquanto não tenha se mostrado suficiente à obtenção da indicação então pretendida, restanos, tão somente, trazer à lume o material então apresentado, com o fito de que venha a ser analisado por um público mais amplo - aliás, nos moldes da sabatina pública por que passava qualquer candidato ao "doutoramento" durante o procedimento que outrora se conduzia no âmbito da universidade medieval. Que venham, pois, as críticas mordazes do leitor voraz.

A única alteração que se fez no texto seguinte corresponde à transposição - quando possível e sem prejuízo para a adequada compreensão do sentido da exposição - das referências bibliográficas lançadas originalmente no corpo do texto (e que nesta versão integrarão, quando possível, as notas de rodapé que o acompanham). Contudo, nenhuma inovação - mesmo quanto a esse particular aspecto (salvo ao aludido reposicionamento) - foi promovida, preservando-se a integridade do documento então produzido.

Faça-se, apenas, uma ressalva: o texto apresentado é incompatível com as extensas (e fatigantes) notas de rodapé que acompanham os escritos que temos a oportunidade de produzir esporadicamente. Peculiaridade decorrente das circunstâncias em que tal exposição foi ultimada. Pois, por óbvio, a abundância dos materiais de pesquisa, bem como a vastidão dos temas abordados se mostra incompatível com a necessidade de síntese que então nos premia. Naturalmente, assim, procurou-se desenvolver um estudo sério, estruturado, balizado e - sobretudo - estribado na demonstração atrelada à enunciação da autoridade de algum "caput scholae" que se dedicou "ex professo" ao assunto tratado.

** Bacharel, Mestre (2006) e Doutor ("summa cum laude") em Direito Civil pela Universidade de São Paulo (2010). Professor Titular da Faculdade de Direito de São Bernardo do Campo (FDSBC). Professor do Centro de Extensão Universitária (IICS/CEU), da Coordenadoria Geral de Especialização, Aperfeiçoamento e Extensão da Pontifícia Universidade Católica de São Paulo (COGEAE-PUC/SP), do Curso de PósGraduação (Especialização) da Fundação Getúlio Vargas (GVLaw-FGV), do Curso de Pós-Graduação "Lato Sensu" da Faculdade de Direito Damásio de Jesus (FDDJ) e da Associação Brasileira de Agentes da Propriedade Industrial (ABAPI). Consultor de Lilian de Melo Silveira Advogados Associados. E-mail: estevan.pousada@direitosbc.br. 
Keywords: Roman law. Medieval university. "Mos italicus". "Mos gallicus". Codification.

$\S$ 1. Introdução: o declínio do Direito Romano no "Ocidente" com a queda de Roma (476 d.C.). A queda do Império Romano do Ocidente assinala não apenas o encerramento da Idade Antiga (e a inauguração da Alta Idade Média), mas também o declínio do Direito Romano na feição ocidental do Império, outrora dividido por Diocleciano; sob o prisma estritamente jurídico (ou seja, tomando-se em consideração o panorama das fontes do direito romano), pode-se dizer que a evolução do direito no Ocidente não ultrapassa o período pós-clássico, beneficiando-se tal porção do "extinto" Império dos "benefícios" da cristianização e da centralização da produção legislativa, conquanto não tenham aí influído, ao menos em um primeiro momento, os resultados da obra sintetizadora justinianéia. Com efeito, nesta porção do Império Romano encontraremos, em princípio, uma projeção tão somente de fontes como o Código Teodosiano, o Epítome de Gaio, as obras de juristas como Paulo e Papiniano, além de fragmentos de compilações privadas, como os Códigos Gregoriano e Hermogeniano; tudo reunido em uma obra de síntese, típica do domínio visigótico, designada por "Lex Romana Visighotorum".

$\S 2$. Questão prejudicial I (conjectura): a permanência de um direito romano "vulgarizado", com projeção, inclusive, no âmbito peninsular. Feitas tais considerações, resta cercada de cautela - quando não mesmo controvertida - a alusão a um "renascimento" do direito romano por meio da universidade medieval. Com efeito, conquanto inegável sua importância no que concerne ao resgate do direito romano justinianeu, não se pode desprezar a influência que, durante toda a Idade Média Alta, o "direito romano pósclássico" desenvolveu na porção ocidental do Antigo Império Romano. ${ }^{1}$

$\S$ 3. Questão prejudicial II (na Península Ibérica): a influência durante o período de dominação visigótica de um direito pós-clássico, com influência cristã e centralizadora. Com efeito, a análise da evolução histórica por que passou o direito romano nos revela que nem sempre todas as suas fontes se evidenciaram providas de uma mesma exuberância e vigor; assim, os costumes, as leis e os plebiscitos, que outrora desempenharam uma função significativa, agora (estamos a falar do período pós-clássico) cedem espaço a fontes diversas, com especial destaque às constituições imperiais. Por tal razão, este direito romano que remanesce nas fontes bárbaras (“leges romanorum") tem um acentuado perfil centralizador, evidenciado pela preponderância

Remetendo aos "Usatges" e aludindo a um "hipotético" pré-renascimento do Direito Romano - ao mesmo tempo em que analisa acuradamente o espectro semântico da expressão "direito romano vulgar"-cf. CRUZ, G. Braga da. Direito romano vulgar ocidental. In: Obras Esparsas I. Coimbra: Imprensa da Universidade, 1979. p. 317 e seguintes. Por uma abordagem mais panorâmica - conquanto sempre problemática - do tema, cf. ainda MEREAA, M. P. Resumo das lições de história do direito português feitas na sua lectura de $1924-$ 1925. Coimbra: Coimbra Editora, 1925. p. 110-118 (especialmente p. 112). 
dos Códigos Teodosiano, Hermogeniano e Gregoriano, em detrimento das autoridades de Paulo ("Sententiae"), Papiniano ("Responsorum") e da jurisprudência clássica; com efeito, tal manancial será extremamente importante no esforço que os primeiros monarcas (particularmente no contexto português) dispensarão, no sentido da mitigação das fontes populares e conciliares - incluam-se aí também as oriundas das Cortes - em detrimento de um processo de centralização da produção legislativa. ${ }^{2}$

$\S$ 4. A história tradicional: o surgimento da universidade medieval sob os moldes de uma corporação de ofício. Observe-se que grande parte da evolução tecnológica humana não decorre da invenção de novos instrumentos, mas sim da atribuição - a instrumentos preexistentes - de novas funções (divisadas pelo usuário). Assim, a "universidade medieval" não desponta como uma criação ab-rupta ("ex novo"), mas sim com base na experiência preexistente das "corporações de ofício"; de fato, espontaneamente despontam na Baixa Idade Média - ora por iniciativa dos alunos, ora de seus mestres - as primeiras universidades. Paris, Oxford, Bolonha... Exemplos mais lapidares, respectivamente, do centro de produção intelectual devotada à teologia, à filosofia, ao direito. Mas o surgimento da "universitas magistrorum et scholarum" não coincide com a opulência que podemos divisar em uma história contemplativa de uma realidade já desenvolvida (conquanto não acabada); em verdade, o início da universidade medieval é caracterizado pela simplicidade e pela participação ativa dos estudantes. Cientes de que certo professor passaria pela localidade, se arregimentavam no sentido de obter do mestre seus valiosos conhecimentos; ainda mais valiosos em um cenário no qual "inexistiam" (quase) as obras de consulta com que estamos familiarizados. ${ }^{3}$

$\S 5$. A fundação do Estudo Dionisiano. Como não poderia deixar de ser, ainda que com um ligeiro atraso, Portugal também contou com uma universidade, já em 1290, conforme se pode depreender da Bula papal que autorizou a criação do Ensino Dionisiano. Com efeito, a tradicional Universidade de Coimbra de hoje conta com mais de sete séculos de existência, caracterizada por profundas reformulações pedagógicas que assinalam sua história. Contudo, por ora, basta-nos destacar que até meados do século XIII os estudantes portugueses não eram formados senão à custa do recurso a pessoal e instituições estrangeiros, nem sempre a recebê-los de maneira extremamente calorosa e gentil. De fato, os estrangeiros agrupavam-se em "nationes" nas diversas universidades de então (tomemos Bolonha, por exemplo); após seus estudos, no mais das vezes, retornavam às suas origens. Uma ou outra exceção poderia se verificar, por meio de estudantes mais brilhantes que permaneceram na Universidade, após a realização dos respectivos exames,

Vide, p. ex., Afonso II e a transição do monarca submetido às Cortes à gênese do absolutismo em Portugal. A respeito, cf. ALVES, J. C. Moreira. Universidade, cultura e direito romano. Revista Trimestral de Jurisprudência dos Estados, 121, p. 1-2, 1994; bem como CRUZ, G. Braga da. Origem e evolução da universidade. In: Obras Esparsas IV, 2. pt. Coimbra: Imprensa da Universidade, 1985. p. 194-195. 
com o intuito de ali lecionar. Toda a vida universitária era cercada de um "ritual" bastante diferente do que podemos divisar hoje: durante o seu "doutoramento", por exemplo, o candidato era primeiramente examinado em sessão secreta, por uma Banca Examinadora (presidida por seu mestre orientador) que deveria trata-lo como se "filho" fosse; após, era então lançado às "feras" (os estudantes), que indagavam o postulante de modo a realizar uma avaliação mais "cerrada" de seus conhecimentos. Prova de fogo, esta, que não apenas destaca a imensa capacidade dos principais intelectuais medievais, mas também serve de contraponto ao corriqueiro lugar comum de considerar a Idade Média um tempo de "trevas"; trevas de onde promanou um Tomás de Aquino? ${ }^{4}$

$\S 6$. O surgimento da Escola dos Glosadores no Estudo de Bolonha: o renascimento do direito romano justinianeu na Europa. Nesse contexto a Escola de Artes de Bolonha acaba por ser brindada com um precioso achado: uma coleção de direito justinianeu é encontrada por Irnério (“Lucernae Iuris"), dando-se ensejo às primeiras investigações debruçadas em um material jurídico aparentemente perdido durante muito tempo. Seus primeiros discípulos - Martinho, Búlgaro, Hugo e Tiago - são retratados em curiosa passagem (de fundo lendário) sobre a morte de seu predecessor, que em seu leito de morte acaba por escolher aquele com quem mais se identificava ("Búlgaro é brilhante; Martinho é um grande conhecedor de leis; Hugo é excelente intérprete; Tiago é como eu"). ${ }^{5}$ Dá-se ensejo à formação da primeira linhagem de estudiosos debruçados sobre as fontes justinianéias recém-encontradas (Escola dos Glosadores); o nome da tendência está atrelado ao método "literal" de interpretação das passagens das fontes - em uma tendência similar àquela evidenciada pela "Escola da Exegese" francesa de séculos mais tarde - estribado na elaboração de "pequenos" comentários, de início "marginais" (e posteriormente mesmo "interlineares"), voltados à elucidação do específico trecho sob exame. Não havia, pois, uma preocupação inicial de cunho "sistemático"; o único objetivo pragmático que se podia entrever era, à primeira vista do método italiano, o de obter uma solução que fornecesse auxílio à solução de problemas práticos da época.

$\S 7$. O "objeto" de trabalho dos Glosadores; resultados alcançados. A "Escola dos Glosadores" se debruçou sobre um "Corpus Iuris Civilis" com uma configuração particular: com base em estudos preparatórios que forneciam ao analista o arcabouço técnico relacionado ao "trivium" e ao "quadrivium", 6 os estudiosos encontravam diante

4 A respeito da matéria do tópico, cf. pela fundação do "Estudo Dionisiano", ROCHA, M. A Coelho da. Ensaio sobre a historia do governo e da legislação em Portugal para servir de introdução ao Estudo do Direito Pátrio. Coimbra: Imprensa da Universidade, 1861. p. 87-89. Pela descrição da vida universitária o precioso estudo de CORREIA, A. A universidade medieval. Revista da Faculdade de Direito da Universidade de São Paulo, v. 45, p. 292-ss, 1950.

5 Objeto de referência em CALASSO, F. Medioevo del diritto. Milano: Giuffrè, 1954. p. 512-ss e TOMASETTI JR., A. Escola de Bolonha. In: Enciclopedia Saraiva de Direito 12, p. 60.

6 Cf. WIEACKER, F. Privatrechtgeschichte der Nuzeit. 2. ed., trad. Port. de António Manuel Botelho Hespanha, História do direito privado moderno, Lisboa, Fundação Calouste Gulbenkian, p. 45-46). 
de si uma obra dividida em 5 partes, bastante heterogêneas: o "Digesto Velho" (D.1 a D. 24,2), o "Digesto Esforçado" (D. 24, 3 a D. 38), o "Digesto Novo" (D. 39 a D.50), o "Código" (9 primeiros livros) e um pequeno "Volume", no qual se encontravam os três livros derradeiros do "Código", as "Institutas", as "Novelas" normas de origem feudal ("libri feudorum") e constituições esparsas do Sacro Império Romano Germânico. Com base em tal material, e iluminados metodologicamente pela dialética escolástica, desenvolveram uma variada obra científica, caracterizada, ora pelo poder de síntese ("regulae iuris" ou brocardos), ora pela análise minudente de posições respeitáveis destoantes ("dissensiones dominorum"); ora pelo método problemático ("quaestiones"), ora ainda pelo ponto de partida concreto ("casus"). Com efeito, em certos assuntos, obras de abrangência inalcançável (e de profundidade insuperável) foram desenvolvidas a respeito de temáticas específicas ("summae"). ${ }^{7}$

§ 8. O apogeu da "Escola dos Glosadores" e a "Magna Glosa" de Acúrsio; os pós-glosadores. A síntese do trabalho desenvolvido pelos glosadores pode ser encontrada na "Magna Glosa" de Acúrsio. Em trabalho de "síntese" (mais do que de verdadeira criação), este estudioso assinalou o ápice do desenvolvimento de sua linhagem intelectual; como teremos a oportunidade de destacar posteriormente, a obra de Acúrsio ofereceu um grande préstimo ao desenvolvimento do direito português no próprio contexto das Ordenações do Reino de Portugal. Após o seu desaparecimento outros nomes acabaram por despontar, sem que se lhes possa atribuir a posição de continuadores da obra de Acúrsio. Desempenharam, pois, um papel de transição entre esta escola e a "Escola dos Comentadores", que a sucedeu; por tal razão, o emprego da expressão "pós-glosadores" deve ser feito como sinônimo de "pós-acursianos" (em fase de transição), mas não de "comentadores". 8

$\S$ 9. A "Escola dos Comentadores" e a preocupação de desenvolvimento de um estudo "sistemático" " partir" do "Corpus Iuris Civilis". A abordagem que a "Escola dos Comentadores" conferiu à compilação justinianéia foi metodologicamente distinta daquela levada a efeito pelos "glosadores": ainda que estes pudessem estar comprometidos com preocupações práticas (inerentes ao "mos italicus"), nunca pretenderam haurir do "Corpus Iuris Civilis" (denominação medieval conferida por Dionísio Godofredo) um "sistema". De fato, esta é a raiz da diferença "metodológica" que se desenvolveu entre os "glosadores" e os "comentadores"; se nos for permitida uma analogia, poderíamos dizer que os "glosadores" partiam da ideia de direito como "dado"; os "comentadores", em uma perspectiva um tanto mais evoluída, o compreendiam como um "construído".

A respeito de tais observações, cf. por todos, COSTA, M. J. de Almeida. História do direito português. 3. ed. Coimbra: Almedina, 2000. p. 214.

8 A respeito da matéria versada, bem como de expoentes como Placentino e Azo, cf. COSTA, M. J. de Almeida. La présence d'Accurse dans l'histoire du Droit Portugais. Boletim da Faculdade de Direito da Universidade de Coimbra 41 (1965), p. 47-ss. 
Por isso, pode-se dizer, lançando mão da autoridade de M. P. Merêa que a "Escola dos Comentadores" não se desenvolveu "sobre", mas sim "a partir" das fontes justinianéias outrora resgatadas por Irnério e seus sequazes. ${ }^{9}$

$\S$ 10. A influência do direito comum em Portugal: "glosadores" e "comentadores" a formar mentalidades e a suprir as deficiências sistemáticas de um modelo. As idéias e métodos de trabalho desenvolvidos pelos "glosadores" e "comentadores" não permaneceram alheias à realidade jurídica lusitana. Bem ao contrário, tão logo possível (D. João I) os estudiosos conimbricenses pretenderam um contato direto com as fontes justinianéias, sem a intermediação do elemento "castelhano" que provisoriamente fezlhe as vezes de intermediário ("Flores del Derecho", "Dotrinal", "Nueve tienpos delos pleytos" de Mestre Jácome das Leis e "Fuero Real", "Especulo" e "Siete Partidas" de D. Afonso X, o Sábio). Em um primeiro momento foi providenciada a tradução do "Código de Justiniano" e das principais obras dos "glosadores" e "comentadores", com destaque para os comentários de Bártolo; a respeito dessa realidade nos dá notícia a "célebre" "Carta de Bruges", na qual se enaltecem as vantagens de um recurso direto às fontes justinianéias (bem como à "ciência jurídica" que sobre elas se desenvolveu). Tal influência, que primeiramente alcança a "mentalidade" dos juristas, dentro em pouco repercutirá na própria conformação do sistema: os diversos sistemas de "direito subsidiário" desenvolvidos nas sucessivas “Ordenações do Reino de Portugal” (O. Af. II, 9; O. Man. II, 5; O. Fil. III, 64) conferiram a Acúrsio e Bártolo o papel de mecanismos de colmatação das lacunas das codificações respectivas. Note-se que, compreendendo tais coletâneas como "sistemas" de direito positivo, não era de se estranhar o reconhecimento de imperfeições (lacunas) passíveis de correção por meio de expedientes integrativos; isso há quase seis séculos atrás. Seria a concepção do ordenamento jurídico uma novidade de pouco tempo atrás? Parece-nos, definitivamente, que não; e para a ereção de um tal modelo, de fundamental importância foi o positivismo científico das duas escolas referidas. ${ }^{10}$

$\S$ 11. Dois métodos de trabalho: "mos italicus" e "mos gallicus". A utilização que se fez das fontes justinianéias não foi absolutamente a mesma nos vários contextos da Europa. Duas variantes principais surgiram, uma na França e outra na Itália. Curiosamente, cada uma delas não se consagrou em seu território de origem; mas, de uma forma ou de outra, deram ensejo a duas formas bastante distintas de se analisar o direito romano justinianeu. Para os adeptos do "mos italicus" as preocupações práticas eram

9 Direito romano, direito comum e boa razão. In: Boletim da Faculdade de Direito da Universidade de Coimbra 16 (1940), p. 539-543.

10 A respeito da temática abordada neste item, cf. COSTA, M. J. de Almeida. Romanismo e bartolismono direito português. Boletim da Faculdade de Direito da Universidade de Coimbra 36 (1960), p. 16-ss; do mesmo autor; Para a história da cultura jurídica medieval em Portugal. Boletim da Faculdade de Direito da Universidade de Coimbra 35 (1959), p. 253-276; e ALBUQUERQUE, M. de Bartolo e bartolomismo na História do Direito Português. Boletim do Ministério da Justiça 304 (1981), p. 13-ss. 
preponderantes, buscando-se sempre que possível extrair das fontes a "ratio" prática, solucionadora de um problema emergente. Nesse contexto metodológico, o "direito romano" (somado ao "direito canônico" na fórmula "ius commune") seria um elemento de conformação de um sistema jurídico atual, não ostentando uma natureza eminentemente contemplativa. Este método alcançou largo desenvolvimento em praticamente toda a Europa, quando foi surpreendido pelo despontar de uma metodologia historicamente comprometida e crítica: o "mos gallicus". Esta técnica, de verniz científico indiscutível, deu ensejo ao surgimento da "Escola Culta", que se projetou em setores esparsos da Europa (Holanda, p.ex.) sem que tenha atingido hegemonia na própria França. Teve por expoente máximo Cujácio e encontrou em António de Gouveia sua projeção mais significativa em meio português; sua predileção pela investigação filológica por vezes lhe rendeu a atribuição de exageros, tais como a caça indiscriminada às "interpolações". Contudo, seu influxo humanista foi precioso, e em Portugal, se não chegou a prevalecer, abalou o prestígio do critério puramente numérico da "communis opinio doctorum", dando oportunidade à consagração do famoso "critério misto". ${ }^{11}$

$\S 12$. A prevalência do método prático escolástico-bartolista na Universidade de Coimbra; reações. Durante o período anterior ao consulado pombalino (reinado de D. José I), o ensino na Universidade de Cimbra estava a cargo dos jesuítas que a comandavam. E a situação portuguesa não era muito diversa, no geral, daquela que se vivenciava em toda a Europa: método "analítico", de caráter "escolástico-bartolista", descomprometido com uma abordagem panorâmica das disciplinas. Pedagogia "hermética" que redundava no "critério do número" e na ausência de uma preocupação com maior grau de certeza, que ao menos teoricamente deveria prevalecer no "foro". Não tardou e na primeira metade do século XVIII já se faziam sentir as primeiras investidas intelectuais contra a metodologia prevalecente, capitaneadas pelo médico Ribeiro Sanches e pelo clérigo Luís António Verney. Este último, por meio de seu "Verdadeiro Método de Estudar" (1746) questionou acidamente os frutos que o "direito comum" (e particularmente o "Direito Romano") legava à mocidade que saía da Universidade mal preparada para os desafios da vida prática. Encampadas tais reformas por Sebastião José de Carvalho e Melo (Marquês de Pombal), estas se projetaram: em uma primeira linha, sobre a disciplina de algumas questões específicas (p. ex. o direito sucessório); além disso, no âmbito da prática forense, com a reafirmação da autoridade do direito nacional, em detrimento da influência excessiva do direito romano; finalmente, via reformulação pedagógica

11 A respeito, cf. no âmbito geral, CANNATA, C. A. Histoire de la jurisprudence européenne. trad. esp. Historia de la ciência jurídica europea. Madrid: Tecnos, 1996. p. 142-149; no ambiente lusitano, MARQUES, M. R. Codificação e paradigmas da modernidade. Coimbra: Coimbra Editora, 2003. p. 19-79; SILVA, N. E. Gomes da. Humanismo em Portugal no século XVI. Tese. Faculdade de Direito da Universidade de Lisboa, passim; do mesmo autor: História do direito português. 3. ed., Lisboa: Fundação Calouste Gulbenkian. p. 181 -ss. 
do ensino universitário, com a edição dos Estatutos (Novos) da Universidade de 1772 , que complementaram a iniciativa lançada na Lei de 18 de agosto de 1769 (Lei da Boa Razão). Tudo isso após uma ácida crítica ao modelo escolástico-bartolista deduzida no "Compêndio Histórico sobre o Estado da Universidade de Coimbra ao tempo da invasão dos jesuítas". ${ }^{12}$ Era necessário, pois, lançar as bases de um "uso moderno" do direito justinianeu ("usus modernus pandectarum"), embebido no método histórico-crítico "cujaciano" e bem informado sobre matérias especiais, como a diplomacia, a economia, o "direito das gentes" e a "história do direito".

$\S 13$. O primeiro elemento de declínio "sistemático" do Direito Romano: o advento do "Code Civil" (1804). O declínio sistemático do direito romano se inicia, verdadeiramente, com o advento do movimento codificador; editado o "Code Civil" em 1804, a França acabou por desencadear o movimento sistemático de repulsa pelo direito romano, ao menos segundo a perspectiva prática defluente do "mos italicus". Conquanto tenha sido precedido pelo Código Prussiano em questão de alguns anos, o Código de Napoleão assinalou a incursão legislativa em um sistema construído "ex novo", a partir das diretrizes hauridas do jusnaturalismo racionalista. Por exemplo, rechaçou-se o "sistema da tradição" em detrimento do acolhimento da transferência da propriedade "solo consensu", tal como preconizada pelo romanista (e "jusracionalista") Hugo Grócio. Com isso, foi efetuada uma aproximação precipitada entre o "direito romano" e o "antigo regime"; liberdade, igualdade e propriedade (lemas originários da Revolução tal como se pode depreender da carta do ano III, 1791), lemas inconciliáveis com o "status quo" representado pelo "direito comum", que servira de sustentáculo, pois, ao Antigo regime, absolutista. Estava anunciada, no cenário europeu, a crise do direito romano, que desenvolveria seu próximo capítulo a propósito da polêmica sobre a codificação na Alemanha, objeto de análise no item subseqüente.

$\S 14$. A polêmica sobre a codificação alemã; seu desfecho; o destino "negro" do direito romano prenunciado por P. Koschaker. O advento da codificação civil francesa, erigida em bases "inteiramente" racionais, foi o primeiro fator de estímulo à sua difusão por toda a Europa. Na atual Alemanha, por sua vez, tal expediente (avançado para a época) talvez pudesse ser tomado como estímulo à empresa "unificadora". Nesse sentido, A. S. J. Thibaut difundiu estudo sobre a necessidade de adoção da fórmula codificadora pela nacionalidade - inclusive como mecanismo facilitador de um novo arranjo político. Contudo, a proposta do autor foi lapidarmente refutada por F. K. von Savigny, em opúsculo no qual versava sobre a "vocação" da época para a legislação e para a jurisprudência.

12 Pela abordagem da questão, cf. CRUZ, G. Braga da. O direito subsidiário na história do direito português. In: Obras Esparsas IV. Coimbra: Imprensa da Universidade, 1973, passim; POUSADA, E. Lo Ré. Preservação da tradição jurídica luso-brasileira: Teixeira de Freitas e a Introdução à Consolidação das Leis Civis, São Paulo, Dissertação (Faculdade de Direito da Universidade de São Paulo), 2006, passim. 
Não nos cabe, aqui, tecer considerações sobre quem se sagrou vencedor da disputa. É fato que, noventa e dois anos após a promulgação do "Code Civil", a Alemanha também adotou a solução codificadora (BGB). As "Pandectas" de Windscheid, que eram reputadas declaração do direito vigente na Alemanha de final do séc. XIX, haviam perdido a sua autoridade (ao menos era o que se pensava). Em Itália a situação era semelhante antes do advento do "Codice Civile" de 1865. O que fazer, pois, com os estudos romanísticos? Havia acabado o legado do Direito Comum? Com a difusão do "programa do Partido Nacional Socialista", já no segundo quartel do século XX, a profecia de P. Koschaker era clara: era melhor estudar o "direito romano" sob a forma de "elegantes" introduções históricas a estudos "dogmáticos" do que ver o seu cultivo desaparecer por completo. ${ }^{13}$

$\S 15$. Ocaso do Direito Romano? O novo florescimento do direito romano como elemento de questionamento e harmonização jurídicos. Qual a perspectiva desse direito que havia renascido na Universidade medieval? Estava realmente morto (ou com sua morte anunciada tal qual preconizada por P. Koschaker)? Pensamos que não. Sob o prisma metodológico, são inegáveis as proximidades entre o método "casuístico" que as "cláusulas gerais" suscitam e a herança romana, sobretudo clássica; os adeptos do sistema do "Common Law", por razões sistemático-metodológicas, partem necessariamente do problema, do elemento concreto, para a solução da hipótese. Por tal razão, a metodologia do direito comum não pode ser desprezada pelo estudioso moderno. Sob o prisma do conteúdo, conceitos como "lesão", "bilateralidade", "arbitragem" e "gratuidade" parecem chamar a atenção do jurista moderno para o cenário de outrora. Por fim, em tempos de tendência à "harmonização" jurídica, existiria manancial mais autorizado para fazer ceder o individualismo das diversas nações europeias? Talvez não. ${ }^{14}$

São Paulo, junho de 2011.

13 A respeito da matéria do item, cf. ZIMMERMANN, R. Europa y el derecho romano. Madrid-BarcelonaBuenos Aires, Marcial Pons, 2009. p. 67-69; KOSCHAKER, P. Europa und das Romischen Rechts. trad. esp. Europa y el derecho romano (de autoria de José Santa Cruz Teijeiro). Madrid: Editorial Revista de Derecho Privado, p. 441-ss; do mesmo autor, Die Krise des Römischen Rechts und die romanistische Rechtwissenschaft. p. 83-84, "apud" J. C. Moreira Alves, Universidade, cultura, cit. (item 4).

14 A respeito, cf. A. Cavanna, Storia del diritto modernoin Europa - Le fonti e il pensiero giuridico, Milano, Giuffrè, 1982, pp. 75-ss. 